\title{
Survival and outcomes after lung transplantation for connective tissue disease-associated interstitial lung diseases
}

\author{
Xiucheng Yang ${ }^{1} \cdot$ Dong Wei $^{1} \cdot$ Mingzhao Liu ${ }^{1} \cdot$ Bo Wu ${ }^{1} \cdot$ Ji Zhang ${ }^{1} \cdot$ Hongyang Xu ${ }^{1} \cdot$ Shugao Ye ${ }^{1} \cdot$ Feng Liu ${ }^{1} \cdot$ \\ Chunxiao $\mathrm{Hu}^{1}$. Jingyu Chen ${ }^{1}$
}

Received: 28 October 2020 / Revised: 22 February 2021 / Accepted: 16 March 2021 / Published online: 23 March 2021

(C) International League of Associations for Rheumatology (ILAR) 2021

\begin{abstract}
Background Lung transplantation (LTx) is the most important treatment for end-stage lung diseases. However, the treatment of connective tissue disease-associated interstitial lung diseases (CTD-ILD) using LTx is still controversial especially for polymyositis/dermatomyositis-associated interstitial lung disease (PM/DM-ILD).

Methods Patients diagnosed with idiopathic pulmonary fibrosis (IPF) $(n=180)$ and CTD-ILD $(n=36)$ from $1^{\text {st }}$ January 2015 to $31^{\text {st }}$ December 2019 were recruited into the study. We set polymyositis/dermatomyositis (PM/DM) as a single subgroup, and all the patients underwent LTx at the Wuxi People's Hospital.

Results We found that patients with non-myositis connective tissue-related ILD (NM-CTLD) were younger ( $p=0.007)$ and had a higher percentage of females $(p=0.000)$ than patients with IPF. PM/DM-ILD was associated with a higher incidence of primary graft dysfunction (PGD) $(p=0.006)$ and a longer time in the intensive care unit (ICU) $(p=0.000)$. The cumulative survival rates of patients with PM/DM-ILD were significantly lower than those with IPF (log rank, $p=0.003$ ). However, there were no significant differences when compared with the cumulative survival rates of patients with NM-CTLD and IPF (log rank, $p=0.528)$. Age- and gender-adjusted Cox proportional hazard analyses indicated that post-LTx PGD (HR 1.498, 95\% CI 1.227-1.828, $p=0.000)$ and duration of ICU (HR 1.027, 95\% CI 1.007-1.047, $p=0.000$ ) were the independent contributors of disease status to survival. Lung infection was the leading cause of post-LTx death in the groups, where the incidence was $65.3 \%(47 / 72) \mathrm{in} \mathrm{IPF}, 66.7 \%(8 / 12)$ in NM-CTLD, and $66.7 \%$ (4/6) in PM/DM-ILD.

Conclusions This study found that patients with NM-CTLD had a similar survival outcome with IPF. However, patients with PM/DM-ILD-performed LTx had a lower survival rate than those with IPF.

\section{Key Points}

- Previous studies have shown that the myopathies associated ILD patients had similar post-LTx outcomes with IPF patients. However, our retrospective analysis indicated that patients with PM/DM-ILD-performed LTx had a lower survival rate than those with IPF.

- Patients with NM-CTLD had a similar survival outcome with IPF.

- We also found that PM/DM-ILD was associated with a higher incidence of PGD and a longer time in the ICU.
\end{abstract}

Keywords Connective tissue disease - Lung transplantation · Idiopathic pulmonary fibrosis · Polymyositis/dermatomyositis · Outcomes

\section{Introduction}

Interstitial lung disease (ILD) is one of the most common complications of connective tissue diseases (CTD), and it

Jingyu Chen

chenjy@wuxiph.com

1 Lung Transplant Center, Department of Thoracic Surgery, Wuxi People's Hospital Affiliated to Nanjing Medical University, Wuxi 214023, China includes systemic sclerosis ( $\mathrm{SSc}$ ), rheumatoid arthritis (RA), Sjögren syndrome (SS), polymyositis/dermatomyositis (PM/ $\mathrm{DM}$ ), and mixed connective tissue disease (MCTD). Connective tissue disease-associated interstitial lung diseases (CTD-ILD) and idiopathic pulmonary fibrosis (IPF) have totally different treatment strategies and prognosis despite both diseases having similar clinical and pathological features. Presently, the primary treatment for patients with CTD is the use of immunosuppressants, which can provide significant clinical benefits [1]. However, the chronic progression of 
interstitial lung disease is associated with a poor prognosis and often culminates in death from respiratory failure. A previous study reported that CTD-ILD-hospitalized patients with pulmonary complications who underwent a standard therapy demonstrated an increased risk of death (10-fold) when compared with those who were not hospitalized [2]. Another study reported that the overall survival rate of patients with ILD which is acute exacerbated (AE) was significantly higher than that of acute exacerbation of IPF, but the median survival time of acute exacerbation of CTD-ILD patients was only $35.0 \pm$ 4.2 days [3]. These results indicate that the prognosis of CTDILD patients is significantly better than that of IPF patients, but it is still an important cause of death in CTD patients. Therefore, more effective treatment strategies for the disease are required [4].

Lung transplantation (LTx) is the most important treatment method for end-stage lung diseases because it has an irreplaceable role of reducing mortality and improving the quality of life. Guidelines similar to those for IPF LTx indications can be used for CTD-ILD if the ILD does not respond to medicine treatment, it gradually worsens, and there are no contraindications for LTx [5]. According to the Registry of the International Society for Heart and Lung Transplantation (ISHLT), CTD-ILD patients undergoing LTx comprised only $0.9 \%$ of all lung transplants (564/63530) from 1995 to 2018 [6]. Therefore, the limited number of retrospective studies on CTD-ILD in LTx limits our consideration when adding the end-stage CTD-ILD patients in the lung transplant waiting list. Therefore, it is necessary to conduct a retrospective analysis of CTD-ILD patients who have undergone lung transplantation in order to obtain more evidence.

In this study, we retrospectively evaluated lung transplantation recipients (LTRs) with CTD or IPF from $1^{\text {st }}$ January 2015 to $31^{\text {st }}$ December 2019 at the largest lung transplant center in China. Currently, there are few cohort studies reporting the survival and outcome of polymyositis/ dermatomyositis-associated interstitial lung disease (PM/ DM-ILD) after LTx. Therefore, we separated the analysis of PM/DM-ILD into a subgroup because the available literature could not effectively guide the clinical practice.

\section{Materials and methods}

We conducted this retrospective cohort study at Wuxi People's Hospital, the largest lung transplant center in China, which is affiliated to Nanjing Medical University. We selected patients who underwent LTx including those diagnosed with IPF and CTD-ILD from $1^{\text {st }}$ January 2015 to $31^{\text {st }}$ December 2019. Patients who received combined organ transplants were excluded from the study. All patients were followed up until death or up to $1^{\text {st }}$ August 2020.
Patients diagnosed with CTD-ILD including SS, SSc, RA, systemic lupus erythematosus (SLE), MCTD, undifferentiated connective tissue disease (UCTD), and PM/DM were set as a single subgroup (PM/DM-ILD) for analysis.

Pre-transplant clinical data including gender, age, body mass index (BMI), and pre-LTx mean pulmonary artery pressure (mPAP) were collected for each patient. In addition, postLTx clinical data including procedure type (single or bilateral), time of using extracorporeal membrane oxygenation (ECMO), cold ischemia time of donor lung, duration of intensive care unit (ICU), grade of primary graft dysfunction (PGD), cumulative survival, and duration of follow-up was also collected for each patient.

The post-LTx immunosuppressive programs were based on the lung transplant center of Wuxi People's Hospital. All patients initially received a triple-drug regimen including calcineurin inhibitors (cyclosporine or tacrolimus), antimetabolites (mycophenolate mofetil or mycophenolate sodium), and corticosteroids.

\section{Statistical analysis}

The demographic and clinical characteristics of patients were expressed as the mean \pm standard deviation (SD) of continuous variables, or as the proportion of categorical variables. Count data were compared using $\chi^{2}$ tests, while measurement data between two groups were compared using the independent sample $t$ test. Kaplan-Meier cumulative survival curves were plotted for each disease subgroup, and survival rates between disease groups were compared using the log rank test. Cox proportional hazard analysis was performed after adjusting the age and gender to find out independent risk factors that affect the prognosis. All statistical analyses were performed using SPSS version 19.0 (SPSS, Inc., Chicago, IL, USA), and a 2 -sided $p \leq 0.05$ was considered to be statistically significant.

\section{Results}

\section{Overall cohort}

A total of 674 lung transplants were performed at the hospital from $1^{\text {st }}$ January 2015 to $31^{\text {st }}$ December 2019, of which $26.7 \%$ of the patients had IPF, while $5.3 \%$ had CTD-ILD. The most common diagnoses for the patients with CTD-ILD were RA (27.8\%), SS (22.2\%), and PM/DM (22.2\%) (Table 1).

\section{Clinical and sociodemographic characteristics}

Patients with CTD-ILD were younger and had a higher percentage of females than those with IPF. PM/DM-ILD was associated with a higher incidence of PGD $(p=0.006)$, and 
Table 1 The CTD subgroups

\begin{tabular}{ll}
\hline The subgroups of CTD & $N=36$ \\
\hline Polymyositis/dermatomyositis (PM/DM) & $8(22.2 \%)$ \\
Sjögren syndrome (SS) & $8(22.2 \%)$ \\
Rheumatoid arthritis (RA) & $10(27.8 \%)$ \\
Systemic sclerosis (SSc) & $2(5.6 \%)$ \\
Systemic lupus erythematosus (SLE) & $1(2.8 \%)$ \\
Mixed connective tissue disease (MCTD) & $6(16.7 \%)$ \\
Undifferentiated connective tissue disease (UCTD) & $1(2.8 \%)$ \\
\hline
\end{tabular}

the patients stayed for a longer time in the ICU. There were no significant differences in the age, gender, body mass index (BMI), pre-LTx mPAP, procedure type (single or bilateral lung transplantation), time of using ECMO, and cold ischemia time of donor lung (Table 2).

\section{Survival}

The cumulative survival rates of patients with PM/DM-ILD were significantly lower than those with IPF (log rank, $p=0.003)$, especially in 6 months ( $38 \%$ vs. $73 \%, p=0.04$ ) and 2 years ( $19 \%$ vs. $60 \%, p=0.01)$. There were no significant differences on the cumulative survival rates when PM/DMILD patients were compared with non-myositis connective tissue-related ILD (NM-CTLD) and IPF patients (log rank, $p=0.528$ ). In addition, there was no significant difference in overall survival between PM/DM-ILD and NM-CTLD patients (log rank, $p=0.084$ ) (Fig. 1).

Results obtained after performing age- and gender-adjusted Cox proportional hazard analyses indicated that PGD (HR $1.498,95 \%$ CI $1.227-1.828, p=0.000)$ and duration of ICU (HR $1.027,95 \%$ CI $1.007-1.047, p=0.000$ ) were the independent contributors of disease status to survival (Table 3 ).

Lung infection was the leading cause of post-LTx death between the groups, where the incidence was $65.3 \%$ (47/72) in IPF, 66.7\% (8/12) in NM-CTLD, and 66.7\% (4/6) in PM/ DM-ILD.

Finally, there were no patients with CTD who developed extrapulmonary flare during the follow-up period.

\section{Discussion}

LTx is still an effective treatment option for end-stage CTDILD with respiratory failure, despite there being doubts on whether CTD-ILD should be treated using LTx. ISHLT has identified CTD-ILD as one of the indications for lung transplantation, though some transplant specialists still think that the extrapulmonary flares of the CTD can affect the prognosis of patients. However, there only few studies reporting this association. Studies have shown that SSc can lead to increased acute rejection because of its high incidence of gastrointestinal dysfunction [7]. PM/DM-ILD could increase complications during management of immunosuppression and rehabilitation after transplantation [1]. Some lung transplant centers still list CTD-ILD as a relative contraindication, but some studies have indicated that the long-term survival of patients is not affected even with these extrapulmonary complications $[8,9]$. In addition, some complications such as gastrointestinal dysfunction can be effectively managed at pre- or post-transplantation [10].

According to the data obtained from the Organ Procurement and Transplantation Network, a big retrospective analysis done by Takagishi (2012) found that patients with CTD-ILD ( $n=284)$ who underwent LTx had similar cumulative survival with those with IPF ( $n=4190)$, and a slightly less cumulative survival than those with chronic obstructive pulmonary disease (COPD) $(n=6720)$. The risk of mortality in patients with CTD was increased 6 months after transplant when compared with those with IPF, but the survival difference gradually narrowed with time. The study also included $34 \mathrm{PM} / \mathrm{DM}$ patients, whose post-LTx cumulative survival rate after 6 months was $70.6 \%[11]$.

Another single-center retrospective study showed a similar survival outcome between patients with CTD and IPF. The median overall survival times of CTD and IPF patients were 29.9 and 21.8 months, respectively. In addition, there was no significant difference in the cumulative survival rate (log rank $p=0.613$ ) of CTD-ILD and IPF patients with matching age and gender [12] .

Most of the previous studies on the analysis of patients with CTD (with either SSc or IPF) who underwent LTx indicated that there was no significant difference between the cumulative survival of the two diseases $[9,13,14]$. Using data obtained from the United Network for Organ Sharing, Bernstein et al. (2015) performed a retrospective cohort study of 229 adults with SSc, 201 with PAH, and 3333 with ILD who underwent LTx in the US from $4^{\text {th }}$ May 2005 to $14^{\text {th }}$ September 2012. They found that a diagnosis of SSc may confer an increased risk of death 1 year post-LTx when compared with the diagnosis of ILD, but the risk was similar with that of pulmonary arterial hypertension (PAH) [8].

Courtwright et al. (2017) retrospectively analyzed the survival results of non-scleroderma CTD with lung transplantation using a list obtained from the Scientific Registry of Transplant Recipients. The obtained results indicated that there was no significant differences in survival, acute or chronic rejection, or extrapulmonary organ dysfunction in non-scleroderma connective tissue-related lung disease (NSCTLD) patients who underwent LTx when compared with IPF. Therefore, NS-CTLD should not be considered a contraindication to lung transplantation. The study also incorporated $51 \mathrm{PM}$ and one PM/DM patients, whose adjusted survival rate 
Table 2 Baseline characteristics of CTD and IPF patients before lung transplantation

\begin{tabular}{|c|c|c|c|c|c|}
\hline \multirow[t]{2}{*}{ Variables } & & \multicolumn{3}{|l|}{ Subgroup } & \multirow[t]{2}{*}{$p$ value } \\
\hline & & NM-CTLD & $\begin{array}{l}\text { PM/DM- } \\
\text { ILD }\end{array}$ & IPF & \\
\hline$N$ & & 28 & 8 & 180 & \\
\hline \multirow[t]{6}{*}{ NM-CTLD } & SS & $8(28.6 \%)$ & & & \\
\hline & RA & $10(35.7 \%)$ & & & \\
\hline & $\mathrm{SSc}$ & $2(7.1 \%)$ & & & \\
\hline & SLE & $1(3.6 \%)$ & & & \\
\hline & MCTD & $6(21.4 \%)$ & & & \\
\hline & UCTD & $1(3.6 \%)$ & & & \\
\hline Gender & Male & $12(42.9 \%)$ & $5(62.5 \%)$ & $165(91.7 \%)$ & \multirow[t]{2}{*}{$<0.001$} \\
\hline & Female & $16(57.1 \%)$ & $3(37.5 \%)$ & $15(8.3 \%)$ & \\
\hline Age (y) & & $55.0 \pm 11.8$ & $54.6 \pm 9.9$ & $59.2 \pm 9.3$ & 0.010 \\
\hline BMI & & $21.6 \pm 3.7$ & $23.1 \pm 2.0$ & $21.3 \pm 2.7$ & 0.210 \\
\hline PAPm (mmHg) & & $34.1 \pm 14.5$ & $41.4 \pm 15.6$ & $35.1 \pm 14.2$ & 0.426 \\
\hline \multirow[t]{2}{*}{ Procedure type } & SLT & $22(78.6 \%)$ & $4(50.0 \%)$ & $130(72.2 \%)$ & \multirow[t]{2}{*}{0.282} \\
\hline & BLT & $6(21.4 \%)$ & $4(50.0 \%)$ & $50(27.8 \%)$ & \\
\hline Cold ischemia time (min) & & $\begin{array}{l}403.3 \\
\quad \pm 114.2\end{array}$ & $518.8 \pm 96.1$ & $\begin{array}{l}438.4 \\
\quad \pm 126.0\end{array}$ & 0.063 \\
\hline \multirow[t]{3}{*}{ ECMO } & None & $4(14.3 \%)$ & 0 & $24(13.3 \%)$ & \multirow[t]{3}{*}{0.064} \\
\hline & Intraoperation & $6(21.4 \%)$ & 0 & $63(35.0 \%)$ & \\
\hline & Postoperation & $18(64.3 \%)$ & $8(100.0 \%)$ & $93(51.7 \%)$ & \\
\hline \multirow[t]{4}{*}{ PGD } & Grade 0 & $4(14.3 \%)$ & 0 & $64(35.6 \%)$ & \multirow[t]{4}{*}{0.006} \\
\hline & Grade 1 & $5(17.9 \%)$ & 0 & $30(16.7 \%)$ & \\
\hline & Grade 2 & $8(28.6 \%)$ & $2(25.0 \%)$ & $47(26.1 \%)$ & \\
\hline & Grade 3 & $11(39.3 \%)$ & $6(75.0 \%)$ & $39(21.7 \%)$ & \\
\hline Duration of ICU (d) & & $5.0 \pm 2.7$ & $21.5 \pm 17.3$ & $6.3 \pm 6.6$ & $<0.001$ \\
\hline
\end{tabular}

Data were shown as number (percentage within group) or mean \pm SD

$N$ numbers, $N M$-CTLD non-myositis connective tissue-related interstitial lung disease, $P M / D M$-ILD polymyositis/dermatomyositis-associated interstitial lung disease, $I P F$ idiopathic pulmonary fibrosis, $S S$ Sjögren syndrome, $R A$ rheumatoid arthritis, $S S c$ systemic sclerosis, $S L E$ systemic lupus erythematosus, $M C T D$ mixed connective tissue disease, UCTD undifferentiated connective tissue disease, $B M I$ body mass index, $P A P m$ mean pulmonary artery pressure, $S L T$ single lung transplantation, $B L T$ bilateral lung transplantation, $E C M O$ extracorporeal membrane oxygenation, $P G D$ primary graft dysfunction, $I C U$ intensive care unit

was not significantly different when compared with IPF patients [15]. In addition, some case reports or small retrospective analysis studies focusing on RA [16] and SLE [17] indicated that LTx for CTD and other indications can receive similarly good results [18].

The results obtained in this study indicated that there was no significant difference in the survival rate between patients with NM-CTLD and IPF who underwent LTx, with the results being consistent with the studies listed above.

Another study reported that one-third of PM/DM-ILD patients showed acute progression, and the 3-year survival rate of the acute type (27.3\%) was lower than that of the chronic type (78.8\%) [19]. Diagnosis of acute or subacute PM/DMILD and clinically amyopathic dermatomyositis (CADM) was associated with more than fourfold increase in the risk of death when compared with PM patients. This was consistent with previous studies which reported that the treatment of acute and subacute forms of PM/DM-ILD was more difficult, and so it was associated with a poor prognosis [20].

Results obtained from two other studies which included five idiopathic inflammatory myopathies patients each indicated that their 1-year survival rate was $100 \%$, but one patient died of pneumonia 38 months after transplant $[12,21]$. In addition, there were no extrapulmonary flares. A case report conducted on a 15-year-old PM-ILD female patient who received a double lung transplant reported that the patient died 9 months later and the pathology showed recurrence of myositis-related lung disease [22]. The case study was the first report on the recurrence of PM-ILD in a patient who underwent LTx.

Previous studies, including the two large retrospective analyses, have shown that the myopathies associated ILD patients had similar post-LTx outcomes with IPF patients [11, 15]. However, our retrospective analysis was not consistent 
Fig. 1 Kaplan-Meier cumulative survival curves were plotted for each disease subgroup. PM/DMILD were significantly lower than those with IPF (log rank,

$p=0.003$ ). There were no significant differences between NM-

CTLD and IPF patients (log rank, $p=0.528)$. NM-CTLD, non-

myositis connective tissue-related interstitial lung disease; PM/DMILD, polymyositis/

dermatomyositis-associated interstitial lung disease; IPF, idiopathic pulmonary fibrosis

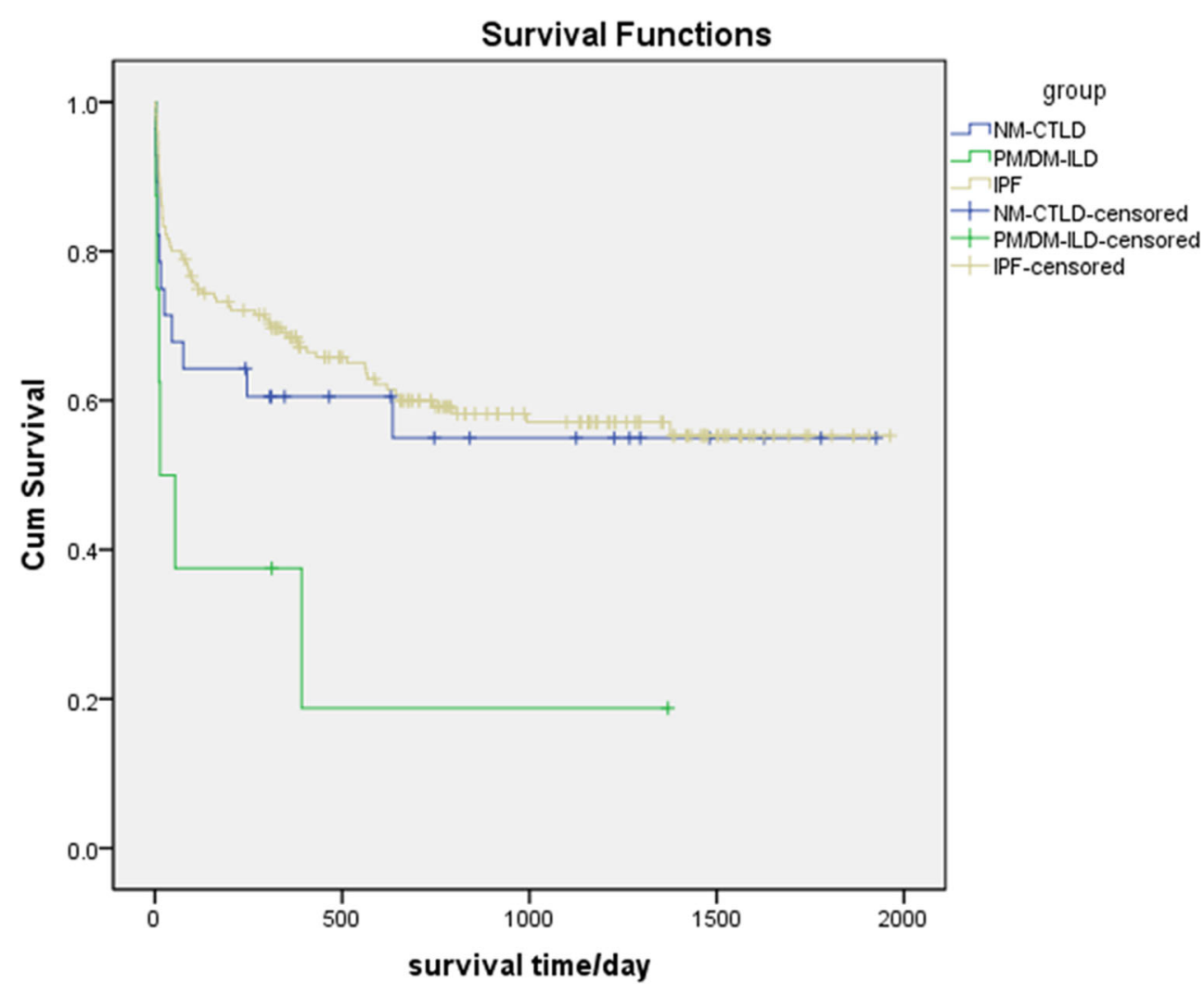

with previous literature reports because the subgroup analysis indicated that patients with PM/DM-ILD-performed LTx had a lower survival rate than those with IPF. This result was mainly due to the lower survival rate observed six months after surgery. The incidence of grade 3 PGD was significantly increased in PM/DM-ILD when compared with IPF, indicating that it was an independent risk factor for survival.
However, this study had some limitations including referral bias, small study size, and the retrospective design used. In addition, we did not have enough follow-up data to compare long-term survival outcomes between the groups. The study is also considered a relatively small-scale study worldwide despite accounting for a large distribution of lung transplantations performed in China. Therefore, additional multi-center analyses are required to confirm our results.
Table 3 Unadjusted and adjusted hazard ratios after lung transplant for patients with CTD versus IPF

\begin{tabular}{llllll}
\hline Variable & \multicolumn{2}{l}{ Univariate analysis } & & \multicolumn{2}{l}{ Cox proportional hazard analyses } \\
\cline { 2 - 3 } & Unadjusted HR and 95\% CI & $p$ value & & Adjusted HR and 95\% CI & $p$ value \\
\hline Gender & $1.301(0.728-2.326)$ & 0.374 & & \\
Age & $0.995(0.974-1.017)$ & 0.665 & & \\
BMI & $1.006(0.932-1.087)$ & 0.872 & & \\
PAPm & $1.005(0.992-1.018)$ & 0.452 & & \\
Procedure type & $1.087(0.674-1.754)$ & 0.732 & & 0.367 \\
Cold ischemia time & $1.000(0.998-1.001)$ & 0.693 & & 0.000 \\
ECMO & $1.549(1.110-2.162)$ & 0.010 & & 0.008 \\
PGD & $1.559(1.278-1.902)$ & 0.000 & & $1.498(1.227-1.828)$ & \\
Duration of ICU & $1.044(1.026-1.062)$ & 0.000 & & $1.027(1.007-1.047)$ & \\
\hline
\end{tabular}

$H R$ hazard Ratios, $B M I$ body mass index, $P A P m$ mean pulmonary artery pressure, ECMO extracorporeal membrane oxygenation, $P G D$ primary graft dysfunction, $I C U$ intensive care unit

After performing age- and gender-adjusted, Cox proportional hazard analyses indicated that PGD and duration of ICU were the independent contributors of disease status to survival 
Although the patients included in this study experienced a global pandemic of COVID-19 during postoperative followup, no one was infected with the novel coronavirus which can be attributed to China's early control of the spread of COVID19. In addition, the patients practiced good habits of wearing masks and hardly going to crowded public places, thereby reducing the bias caused by the COVID-19 epidemic.

\section{Conclusions}

Results obtained from this retrospective analysis indicated that patients with NM-CTLD had a similar survival outcome with IPF, but patients with PM/DM-ILD-performed LTx had a lower survival rate than those with IPF. Therefore, LTx could be the most important treatment strategy for end-stage NMCTLD. However, careful consideration should incorporated for PM/DM-ILD patients when adding them in the transplant waiting list. Finally, the reasons for the high mortality rate in the treatment of PM/DM-ILD using LTx needs further exploration.

Author contribution Y.X.C and C.J.Y designed and performed the study. Y.X.C, W.D, L.M.Z, and W.B collected and analyzed data. Y.X.C wrote the paper. C.J.Y, Z.J, X.H.Y, Y.S.G, L.F, and H.C.X supervised the clinical study and revised the manuscript. All authors approved the final manuscript.

Availability of data and material The datasets used or analyzed during the current study are available from the corresponding author on reasonable request.

Code availability Not applicable

\section{Declarations}

Ethics approval Formal review of the study was deemed unnecessary by the Wuxi People's Hospital affiliated to Nanjing Medical University.

Consent to participate Not applicable

Consent for publication Not applicable

Disclosures None.

\section{References}

1. Mathai SC, Danoff SK (2016) Management of interstitial lung disease associated with connective tissue disease. BMJ 352:h6819. https://doi.org/10.1136/bmj.h6819

2. Ratwani AP, Ahmad KI, Barnett SD, Nathan SD, Brown AW (2019) Connective tissue disease-associated interstitial lung disease and outcomes after hospitalization: a cohort study. Respir Med 154: 1-5. https://doi.org/10.1016/j.rmed.2019.05.020
3. Cao M, Sheng J, Qiu X, Wang D, Wang D, Wang Y, Xiao Y, Cai H (2019) Acute exacerbations of fibrosing interstitial lung disease associated with connective tissue diseases: a population-based study. BMC Pulm Med 19(1):215. https://doi.org/10.1186/ s12890-019-0960-1

4. Navaratnam V, Ali N, Smith CJ, McKeever T, Fogarty A, Hubbard RB (2011) Does the presence of connective tissue disease modify survival in patients with pulmonary fibrosis? Respir Med 105(12): 1925-1930. https://doi.org/10.1016/j.rmed.2011.08.015

5. Weill D, Benden C, Corris PA, Dark JH, Davis RD, Keshavjee S, Lederer DJ, Mulligan MJ, Patterson GA, Singer LG, Snell GI, Verleden GM, Zamora MR, Glanville AR (2015) A consensus document for the selection of lung transplant candidates: 2014-an update from the Pulmonary Transplantation Council of the International Society for Heart and Lung Transplantation. J Heart Lung Transplant 34(1):1-15. https://doi.org/10.1016/j.healun. 2014.06.014

6. Chambers DC, Cherikh WS, Harhay MO, Hayes D Jr, Hsich E, Khush KK, Meiser B, Potena L, Rossano JW, Toll AE, Singh TP, Sadavarte A, Zuckermann A, Stehlik J, International Society for H, Lung T (2019) The International Thoracic Organ Transplant Registry of the International Society for Heart and Lung Transplantation: thirty-sixth adult lung and heart-lung transplantation Report-2019; Focus theme: Donor and recipient size match. J Heart Lung Transplant 38(10):1042-1055. https://doi.org/10.1016/ j.healun.2019.08.001

7. Saggar R, Khanna D, Furst DE, Belperio JA, Park GS, Weigt SS, Kubak B, Ardehali A, Derhovanessian A, Clements PJ, Shapiro S, Hunter C, Gregson A, Fishbein MC, Lynch Iii JP, Ross DJ, Saggar R (2010) Systemic sclerosis and bilateral lung transplantation: a single centre experience. Eur Respir J 36(4):893-900. https://doi. org/10.1183/09031936.00139809

8. Bernstein EJ, Peterson ER, Sell JL, D'Ovidio F, Arcasoy SM, Bathon JM, Lederer DJ (2015) Survival of adults with systemic sclerosis following lung transplantation: a nationwide cohort study. Arthritis Rheumatol 67(5):1314-1322. https://doi.org/10.1002/art. 39021

9. Sottile PD, Iturbe D, Katsumoto TR, Connolly MK, Collard HR, Leard LA, Hays S, Golden JA, Hoopes C, Kukreja J, Singer JP (2013) Outcomes in systemic sclerosis-related lung disease after lung transplantation. Transplantation 95(7):975-980. https://doi. org/10.1097/TP.0b013e3182845f23

10. Gasper WJ, Sweet MP, Golden JA, Hoopes C, Leard LE, Kleinhenz ME, Hays SR, Patti MG (2008) Lung transplantation in patients with connective tissue disorders and esophageal dysmotility. Dis Esophagus 21(7):650-655. https://doi.org/10. 1111/j.1442-2050.2008.00828.x

11. Takagishi T, Ostrowski R, Alex C, Rychlik K, Pelletiere K, Tehrani R (2012) Survival and extrapulmonary course of connective tissue disease after lung transplantation. J Clin Rheumatol 18(6):283-289. https://doi.org/10.1097/RHU.0b013e3182676089

12. Park JE, Kim SY, Song JH, Kim YS, Chang J, Lee JG, Paik HC, Park MS (2018) Comparison of short-term outcomes for connective tissue disease-related interstitial lung disease and idiopathic pulmonary fibrosis after lung transplantation. J Thorac Dis 10(3):15381547. https://doi.org/10.21037/jtd.2018.02.50

13. Schachna L, Medsger TA Jr, Dauber JH, Wigley FM, Braunstein NA, White B, Steen VD, Conte JV, Yang SC, McCurry KR, Borja MC, Plaskon DE, Orens JB, Gelber AC (2006) Lung transplantation in scleroderma compared with idiopathic pulmonary fibrosis and idiopathic pulmonary arterial hypertension. Arthritis Rheum 54(12):3954-3961. https://doi.org/10.1002/art.22264

14. Fernandez-Codina A, Berastegui C, Pinal-Fernandez I, Silveira MG, Lopez-Meseguer M, Monforte V, Guillen-Del Castillo A, Simeon-Aznar CP, Fonollosa-Pla V, Sole J, Bravo-Masgoret C, Roman-Broto A (2018) Lung transplantation in systemic sclerosis: 
a single center cohort study. Joint Bone Spine 85(1):79-84. https:// doi.org/10.1016/j.jbspin.2017.03.012

15. Courtwright AM, El-Chemaly S, Dellaripa PF, Goldberg HJ (2017) Survival and outcomes after lung transplantation for nonscleroderma connective tissue-related interstitial lung disease. J Heart Lung Transplant 36(7):763-769. https://doi.org/10.1016/j. healun.2016.12.013

16. Yazdani A, Singer LG, Strand V, Gelber AC, Williams L, Mittoo S (2014) Survival and quality of life in rheumatoid arthritis-associated interstitial lung disease after lung transplantation. J Heart Lung Transplant 33(5):514-520. https://doi.org/10.1016/j.healun.2014. 01.858

17. Levy RD, Guerraty AJ, Yacoub MH, Loertscher R (1993) Prolonged survival after heart-lung transplantation in systemic lupus erythematosus. Chest 104(6):1903-1905. https://doi.org/10. 1378/chest.104.6.1903

18. de Perrot M, Granton JT, McRae K, Pierre AF, Singer LG, Waddell TK, Keshavjee S (2012) Outcome of patients with pulmonary arterial hypertension referred for lung transplantation: a 14-year singlecenter experience. J Thorac Cardiovasc Surg 143(4):910-918. https://doi.org/10.1016/j.jtcvs.2011.08.055
19. Won Huh J, Soon Kim D, Keun Lee C, Yoo B, Bum Seo J, Kitaichi M, Colby TV (2007) Two distinct clinical types of interstitial lung disease associated with polymyositis-dermatomyositis. Respir Med 101(8):1761-1769. https://doi.org/10.1016/j.rmed.2007.02.017

20. Fujisawa T, Hozumi H, Kono M, Enomoto N, Hashimoto D, Nakamura Y, Inui N, Yokomura K, Koshimizu N, Toyoshima M, Shirai T, Yasuda K, Hayakawa H, Suda T (2014) Prognostic factors for myositis-associated interstitial lung disease. PLoS One 9(6): e98824. https://doi.org/10.1371/journal.pone.0098824

21. Ameye H, Ruttens D, Benveniste O, Verleden GM, Wuyts WA (2014) Is lung transplantation a valuable therapeutic option for patients with pulmonary polymyositis? Experiences from the Leuven transplant cohort. Transplant Proc 46(9):3147-3153. https://doi. org/10.1016/j.transproceed.2014.09.163

22. Arboleda R, Gonzalez O, Cortes M, Perez-Cerda F (2015) Recurrent polymyositis-associated lung disease after lung transplantation. Interact Cardiovasc Thorac Surg 20(4):560-562. https://doi.org/10.1093/icvts/ivu423

Publisher's note Springer Nature remains neutral with regard to jurisdictional claims in published maps and institutional affiliations. 